\title{
Low sensitivity of cloud condensation nuclei to changes in the sea-air flux of dimethyl-sulphide
}

\author{
M. T. Woodhouse ${ }^{1}$, K. S. Carslaw ${ }^{1}$, G. W. Mann ${ }^{2}$, S. M. Vallina ${ }^{3, *}$, M. Vogt ${ }^{3, * *}$, P. R. Halloran ${ }^{4}$, and O. Boucher \\ ${ }^{1}$ Institute for Climate and Atmospheric Science, School of Earth and Environment, University of Leeds, Leeds, LS2 9JT, UK \\ ${ }^{2}$ National Centre for Atmospheric Science, School of Earth and Environment, University of Leeds, Leeds, LS2 9JT, UK \\ ${ }^{3}$ School of Environmental Sciences, University of East Anglia, Norwich, NR4 7TJ, UK \\ ${ }^{4}$ Met Office Hadley Centre, Fitzroy Road, Exeter, Devon, EX13PB, UK \\ * now at: Massachusetts Institute of Technology (MIT), 77 Mass. Ave, Cambridge, USA \\ *** now at: ETH Zürich, Institut für Biogeochemie und Schadstoffdynamik, CHN E 28.1, Universitätstrasse 16, \\ 8092 Zürich, Switzerland
}

Received: 26 January 2010 - Published in Atmos. Chem. Phys. Discuss.: 10 February 2010

Revised: 4 August 2010 - Accepted: 9 August 2010 - Published: 16 August 2010

\begin{abstract}
The emission of dimethyl-sulphide (DMS) gas by phytoplankton and the subsequent formation of aerosol has long been suggested as an important climate regulation mechanism. The key aerosol quantity is the number concentration of cloud condensation nuclei $(\mathrm{CCN})$, but until recently global models did not include the necessary aerosol physics to quantify CCN. Here we use a global aerosol microphysics model to calculate the sensitivity of $\mathrm{CCN}$ to changes in DMS emission using multiple presentday and future sea-surface DMS climatologies. Calculated annual fluxes of DMS to the atmosphere for the five modelderived and one observations based present day climatologies are in the range 15.1 to $32.3 \mathrm{Tg} \mathrm{a}^{-1}$ sulphur. The impact of DMS climatology on surface level CCN concentrations was calculated in terms of summer and winter hemispheric mean values of $\Delta C C N / \Delta$ Flux $_{\text {DMS }}$, which varied between -43 and $+166 \mathrm{~cm}^{-3} /\left(\mathrm{mg} \mathrm{m}^{-2} \mathrm{day}^{-1}\right.$ sulphur), with a mean of $63 \mathrm{~cm}^{-3} /\left(\mathrm{mg} \mathrm{m}^{-2} \mathrm{day}^{-1}\right.$ sulphur $)$. The range is due to $\mathrm{CCN}$ production in the atmosphere being strongly dependent on the spatial distribution of the emitted DMS. The relative sensitivity of CCN to DMS (i.e. fractional change in $\mathrm{CCN}$ divided by fractional change in DMS flux) depends on the abundance of non-DMS derived aerosol in each hemisphere. The relative sensitivity averaged over the five present day DMS climatologies is estimated to be 0.02 in the northern hemisphere (i.e. a $0.02 \%$ change in $\mathrm{CCN}$ for a $1 \%$ change in DMS) and 0.07 in the southern hemisphere where aerosol
\end{abstract}

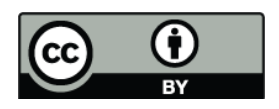

Correspondence to: M. T. Woodhouse (m.woodhouse@see.leeds.ac.uk) abundance is lower. In a globally warmed scenario in which the DMS flux increases by $\sim 1 \%$ relative to present day we estimate a $\sim 0.1 \%$ increase in global mean $\mathrm{CCN}$ at the surface. The largest $\mathrm{CCN}$ response occurs in the Southern Ocean, contributing to a Southern Hemisphere mean annual increase of less than $0.2 \%$. We show that the changes in DMS flux and CCN concentration between the present day and global warming scenario are similar to interannual differences due to variability in windspeed. In summary, although DMS makes a significant contribution to global marine $\mathrm{CCN}$ concentrations, the sensitivity of $\mathrm{CCN}$ to potential future changes in DMS flux is very low. This finding, together with the predicted small changes in future seawater DMS concentrations, suggests that the role of DMS in climate regulation is very weak.

\section{Introduction}

Dimethyl-sulphide (DMS) is an important marine trace gas produced from the degradation of dimethylsulphoniopropionate (DMSP) in the oceans, which is released from some phytoplankton species (Stefels et al., 2007). Some DMS reaches the atmosphere via gas exchange processes (Liss et al., 1997), resulting in a net sea-air global flux of between 13 and $37 \mathrm{Tg} \mathrm{a}^{-1}$ of sulphur (Kettle and Andreae, 2000), depending on the gas flux parameterisation and wind speed dataset used. Gas flux parameterisation accounts for most of this variability.

Once in the atmosphere, DMS is oxidised (Barnes et al., 2006) and the sulphur products can contribute to atmospheric

Published by Copernicus Publications on behalf of the European Geosciences Union. 
aerosol. The chemical conversion begins with the oxidation of DMS by $\mathrm{OH}$ and $\mathrm{NO}_{3}$ and results in the production of $\mathrm{SO}_{2}$, methanesulphonic acid (MSA) and gas-phase sulphuric acid $\left(\mathrm{H}_{2} \mathrm{SO}_{4}\right)$. Sulphuric acid $\left(\mathrm{H}_{2} \mathrm{SO}_{4}\right)$ can condense on existing aerosol particles (Pham et al., 1995) or nucleate to form new sulphuric acid particles (Kulmala et al., 1998). Chemical transport model studies suggest that between 18 and $42 \%$ of global atmospheric sulphate aerosol mass is derived from DMS (Chin and Jacob, 1996; Gondwe et al., 2003; Kloster et al., 2006). Chin and Jacob (1996) also estimated that DMS accounts for $20-80 \%$ of non sea-salt sulphate in surface air over the Northern Hemisphere oceans and over $80 \%$ in most of the Southern Hemisphere and in the upper troposphere.

The formation and emission of DMS in the oceans has been suggested as a way for oceanic phytoplankton to influence climate, via the CLAW hypothesis (Charlson et al., 1987). The hypothesis suggests that as a result of global warming, phytoplankton DMS formation could change, with a subsequent impact on climate. For example, an increased flux of DMS to the atmosphere could yield more sulphate cloud condensation nuclei (CCN), with a subsequent increase in the number of cloud droplets. This would increase the shortwave cloud radiative forcing that would cool the surface and constitute a negative climate feedback. The response of DMS to a warmed climate (and hence the direction of the feedback) is not certain, however (Ayers and Cainey, 2007; Carslaw et al., 2010).

The inclusion of DMS in global atmospheric models requires global fields of DMS seawater concentration from which the net sea-air flux can be calculated. An early attempt to quantify the regional or global sea-air DMS flux was made by Bates et al. (1987). They used seawater DMS concentration measurements from the Pacific and calculated seasonal (summer and winter) mean surface seawater concentrations and fluxes (primarily controlled by season and latitude). Early global atmospheric sulphur model studies (e.g. Langner and Rodhe, 1991; Chin et al., 1996, 1998) calculated atmospheric DMS concentrations based on the seawater concentrations of Bates et al. (1987). Thus these early models did not fully represent the range of spatial and temporal variability in the DMS seawater concentrations.

A global climatology of seawater DMS concentrations from measurements was created by Kettle et al. (1999). Over 15000 measurements were processed to create a monthly varying climatology with $1^{\circ}$ resolution. Large areas of the oceans have sparse observation coverage; the Southern, South Pacific, and Indian Oceans in particular. Kettle et al. (1999) used a system based on the Longhurst et al. (1995) biogeochemical provinces to estimate DMS concentrations in areas where there were insufficient observations. The climatology shows that coastal upwelling zones and high latitude regions have the highest DMS concentrations $(>20 \mathrm{nM})$, while large areas of the open oceans have quite low DMS concentrations (0 to $3 \mathrm{nM}$ ). Kettle et al. (1999) noted that there might be a high latitude summer sampling bias in the observations, as the database (at the time of the original publication) lacked winter DMS measurements at high latitudes. Liss et al. (1994) highlight the importance of the prymnesiophyte Phaeocystis in some Antarctic waters during spring, and the large amount of DMS these blooms produce. An updated field with more measurements was used in Kettle and Andreae (2000), though Vallina et al. (2007) find a correlation coefficient of only 0.62 between the raw observational data and the Kettle and Andreae (2000) climatology. The Kettle and Andreae (2000) climatology is used as the baseline in this study. The very high concentrations of DMS in the Kettle et al. (1999) and Kettle and Andreae (2000) climatologies at high latitudes should be regarded with caution however.

Another climatology of DMS seawater concentrations was produced by Belviso et al. (2004b) based on SeaWiFs satellite ocean colour data. The resulting climatology generally shows less seasonal variation, and lower DMS concentrations than Kettle and Andreae (2000). The SeaWiFs method works well for blooms of mixed phytoplankton types, and blooms dominated by Phaeocystis, but fails for diatom dominated blooms (Belviso et al., 2004b).

Observation based DMS seawater concentration databases have been used extensively in model studies. However, for studies of multi-annual variability, long term trends and climate feedbacks it is necessary to develop a mechanistic model or parameterisation of DMS production and concentration on a global scale. These diagnostic models require evaluation, and one way to do that is to compare them directly against point observations or the interpolated fields of, for example, Kettle and Andreae (2000). Boucher et al. (2003) compared the Kettle and Andreae (2000) observational climatology, the Belviso et al. (2004b) climatology from SeaWiFS satellite chlorophyll, and the model derived climatology of Aumont et al. (2002), in an atmospheric general circulation model (GCM). The three different DMS sources produced only a small range of calculated global DMS flux of between 24 and $27 \mathrm{Tg} \mathrm{a}^{-1}$ sulphur, but with large differences in spatial distribution. Belviso et al. (2004a) examined the differences between seven climatologies: the two observational climatologies of Kettle et al. (1999) and Kettle and Andreae (2000); the light, nutrients and chlorophyll relationship of Anderson et al. (2001), the Simó and Dachs (2002) mixed layer depth (MLD) and chlorophyll-a relationship; the Belviso et al. (2004b) and Aumont et al. (2002) relationships noted above; and a process model described in Chu et al. (2003). They concluded that there are locally up to $100 \%$ differences in DMS seawater concentration, particularly at high latitudes, and that none of the climatologies provides a complete representation of oceanic DMS concentrations. The impact of the different climatologies on sea-air fluxes and sulphate aerosol was not calculated.

Here, we use six present day monthly mean sea-surface DMS climatologies, including Kettle and Andreae (2000), as input to a sophisticated global aerosol microphysics model 
to calculate global fields of atmospheric DMS concentration and CCN. Our aim is to understand how previously reported large differences in DMS seawater concentration affect the climate-relevant $\mathrm{CCN}$ concentration, and to calculate global CCN sensitivities to DMS flux for the first time in a microphysical model. Recognising the importance of wind speed, and not just DMS seawater concentration, as an important influence on the sea-air flux, we quantify DMS changes over two additional years. We also quantify the effect on CCN of changes in DMS in a global warming scenario based on two of the climatologies, and discuss the implications of our findings for the CLAW hypothesis.

\section{Methods}

\subsection{The aerosol model}

We use the Global Model of Aerosol Processes, GLOMAP (Spracklen et al., 2005; Manktelow et al., 2007; Mann et al., $2010)$ in the TOMCAT chemical transport model (Chipperfield, 2006). GLOMAP (in TOMCAT) is driven by European Centre for Medium-Range Weather Forecasts (ECMWF) ERA-40 meteorology (Uppala et al., 2005). The sulphur chemistry scheme has seven sulphur species with six hourly monthly mean fields of $\mathrm{NO}_{3}, \mathrm{O}_{3}, \mathrm{OH}$ and $\mathrm{HO}_{2}$ driving DMS and $\mathrm{SO}_{2}$ oxidation (see Spracklen et al., 2005; Manktelow, 2008). This offline oxidant approach may overestimate the oxidation of DMS, as the oxidants are not depleted as DMS is oxidised. Additionally, we neglect oxidation by halogen species (e.g. $\mathrm{BrO}$ and $\mathrm{Cl}$ ). In this version of the model (GLOMAP-mode) the particle size distribution is represented using a two-moment (mass and number) modal scheme with log-normal modes. The model is described in detail in Mann et al. (2010) and contains internal mixtures of sulphate, sea spray, elemental carbon (EC) and organic carbon (OC) (including secondary organics), and dust. Manktelow et al. (2010) find that the impact of dust on sulphate aerosol is small during a large dust storm. Dust is therefore neglected in this study. The modal version of GLOMAP compares well with the sectional version of GLOMAP, and the microphysical processes are consistent between the two different frameworks, suggesting that the response to perturbations is also likely to be similar between the two models.

Anthropogenic and volcanic emissions follow the AEROCOM recommendations (Dentener et al., 2006), with size assumptions for primary emissions of $\mathrm{EC}, \mathrm{OC}$ and sulphate as in Stier et al. (2005). Sea spray emissions are calculated online in the model using the Gong (2003) parameterisation between 0.035 and $30.0 \mu \mathrm{m}$ dry radius. Microphysical processes include coagulation, condensation, nucleation, and dry and wet deposition. The nucleation scheme is that of Kulmala et al. (1998). The spatial resolution is $2.8^{\circ} \times 2.8^{\circ}$, with 31 vertical levels up to $10 \mathrm{hPa}$.
Sea-air DMS fluxes are calculated based on prescribed global DMS seawater concentrations (baseline: Kettle and Andreae, 2000), with a wind speed dependent air-sea flux parameterisation (here Nightingale et al., 2000). Air-sea fluxes are generally calculated as the product of concentration gradient across the sea-air interface and a piston velocity term, where piston velocity is a non-linear function of wind speed (Liss and Merlivat, 1986). Model air-sea fluxes therefore depend on both sea-surface concentration and wind speeds, which in GLOMAP are updated every six hours.

\subsection{Model DMS climatology descriptions}

The Kettle and Andreae (2000) DMS climatology, described in Sect. 1, is used in this study as the baseline. The other climatologies tested here are calculated in two ocean GCMs, a developmental version of the UK Met Office Diat-HadOCC marine ecosystem model (developed from Palmer and Totterdell, 2001) within the HadGEM2 coupled model, and the PlankTOM5 marine ecosystem model in the OPA-ORCA ocean GCM with the LIM sea-ice model (Timmermann et al., 2005). Fig. 1 shows the annual average surface seawater DMS concentrations for each of the present day climatologies.

Table 1 describes the scenarios in this study. Here the individial climatologies are described. CLIM2 and CLIM3 (Table 1) are from Vallina et al. (2007). They use outputs from PlankTOM5 in the OPA-ORCA-LIM model combined with the Simó and Dachs (2002) and Vallina and Simó (2007) DMS parameterisations. Simó and Dachs (2002) is a diagnostic parameterisation that relates DMS to the MLD and chlorophyll concentration (Simó and Dachs, 2002). The Vallina and Simó (2007) parameterisation relates DMS to the solar radiation dose (SRD) received by the upper mixed layer in the ocean (Vallina and Simó, 2007). The OPA-ORCALIM model provides the global monthly fields of MLD. Chlorophyll concentrations are calculated from the PlankTOM5 marine ecosystem model, coupled to OPA-ORCALIM. The PlankTOM5 model simulates plankton functional types (PFTs) and different nutrients and light limitation (Le Quéré et al., 2005).

Diat-HadOCC is a two-PFT nutrient-phytoplanktonzooplankton-detritus (NPZD) model functioning within the framework of the physical ocean of the HadGEM2 model. Two different DMS parameterisations within Diat-HadOCC are tested here, described in Halloran et al. (2010). The Anderson et al. (2001) DMS parameterisation in CLIM4 uses a relationship, fitted to observations, between chlorophyll, light and nutrients. A minimum DMS concentration of $2.29 \mathrm{nM}$ is specified. The second parameterisation within Diat-HadOCC is based on the parameterisation of Simó and Dachs (2002), modified with Aranami and Tsunogai (2004), to create CLIM5. DMS production in Diat-HadOCC is limited to the non-diatom phytoplankton functional type. 
Table 1. Summarising the differences between the experiments. Aerosol model year refers to the meteorological year that GLOMAP-mode is being forced by. The final column shows calculated annual fluxes of DMS. See text for further details.

\begin{tabular}{cccccc}
\hline Simulation & $\begin{array}{c}\text { Marine } \\
\text { ecosystem } \\
\text { model }\end{array}$ & DMS param. & $\begin{array}{c}\text { Aerosol } \\
\text { model } \\
\text { year }\end{array}$ & $\begin{array}{c}\text { Marine } \\
\text { climate } \\
\text { conditions }\end{array}$ & $\begin{array}{c}\text { DMS flux } \\
\text { Tg a }^{-1} \\
\text { sulphur }\end{array}$ \\
\hline CLIM1 & - & Kettle and Andreae (2000) & 2000 & Present day & 18.6 \\
CLIM2 & PlankTOM5 & Simó and Dachs (2002) & 2000 & Present day & 18.4 \\
CLIM3 & PlankTOM5 & Vallina and Simó (2007) & 2000 & Present day & 17.4 \\
CLIM4 & Diat-HadOCC & Anderson et al. (2001) & 2000 & Present day & 32.3 \\
CLIM5 & Diat-HadOCC & Simó and Dachs (2002) & 2000 & Present day & 19.4 \\
CLIM6 & PlankTOM5 & Vogt et al. (2009) & 2000 & Present day & 15.1 \\
CLIM2_GW & PlankTOM5 & Simó and Dachs (2002) & 2000 & Globally warmed & 18.7 \\
CLIM3_GW & PlankTOM5 & Vallina and Simó (2007) & 2000 & Globally warmed & 17.6 \\
CLIM1_1999 & - & Kettle and Andreae (2000) & 1999 & Present day & 18.4 \\
CLIM1_2001 & - & Kettle and Andreae (2000) & 2001 & Present day & 18.4 \\
\hline
\end{tabular}

CLIM6 is from a process based model in PlankTOM5 in OPA-ORCA-LIM (Vogt et al., 2009). The Vogt et al. (2009) model is a mechanistic model that simulates the biological processes that produce and destroy DMS, while the climatologies CLIM2-CLIM5 were calculated from modelled oceanographic variables with relationships derived empirically from in situ observations.

The Diat-HadOCC model (CLIM4 and CLIM5) produces the strongest seasonal changes, and greater seasonal variability than the PlankTOM5 model (CLIM2, CLIM3, CLIM6). The highest values of sea-surface DMS concentration are also in CLIM4 and CLIM5. The climatology with the least variability is CLIM3. Plots showing seasonal variation in sea-surface concentrations are not shown.

\subsection{Description of the experiments}

Three sets of experiments were conducted to investigate (i) the impacts of different seawater DMS climatologies on atmospheric DMS, sulphate aerosol and CCN, (ii) the potential impact of global warming on DMS emission and aerosol, and (iii) interannual variability of DMS emissions (see Table 1).

In the first set of simulations, five DMS seawater climatologies (based on present-day fields from the PlankTOM5 and Diat-HadOCC marine ecosystem models) were compared against the frequently used Kettle and Andreae (2000) observational climatology (CLIM1), which is the only DMS field derived from in situ observations.

To examine potential future changes in DMS, climatological DMS fields (CLIM2_GW and CLIM3_GW) were derived using the Simó and Dachs (2002) and Vallina and Simó (2007) parameterisations applied to results of the OPAORCA-LIM model using a global warming scenario. The future DMS fields are described in Vallina et al. (2007) based on an increase in atmospheric $\mathrm{CO}_{2}$ concentration from
$377 \mathrm{ppm}$ to $551 \mathrm{ppm}$ over the course of 56 years. The transient climate simulations impact atmospheric temperature and winds, which result in changes to the physical state of the ocean (e.g. MLD, sea-surface temperatures).

The third set of simulations examines the variability in seaair DMS flux resulting from interannual variability in wind speed over the period 1999-2001. This variability is caused by differences in the wind-driven sea-air DMS flux given by the ECMWF meteorological forcing fields. Ocean surface concentrations of DMS follow the Kettle and Andreae (2000) climatology.

All simulations, with the exception of the interannual variability simulations, use year 2000 meteorology. Meteorology, including wind speeds, is thus consistent between simulations. All model results presented below are from monthly mean output.

Absolute and relative differences in DMS and $\mathrm{CCN}$ between experiments are defined as:

$$
\begin{aligned}
& \Delta \text { Flux }_{\text {DMS }, \text { abs }}=\text { Flux }_{\text {DMS ,CLIM\# }}-\text { Flux }_{\text {DMS,CLIM1 }} \\
& \Delta \text { Flux }_{\text {DMS }, \text { rel }}=\frac{\Delta \text { Flux }_{\text {DMS,abs }}}{\text { Flux }_{\text {DMS }, \text { CLIM1 }}} \times 100 \\
& \Delta \mathrm{CCN}_{\mathrm{abs}}=\mathrm{CCN}_{\mathrm{CLIM} \#}-\mathrm{CCN}_{\mathrm{CLIM} 1} \\
& \Delta \mathrm{CCN}_{\mathrm{rel}}=\frac{\Delta \mathrm{CCN}_{\mathrm{abs}}}{\mathrm{CCN}_{\mathrm{CLIM} 1}} \times 100
\end{aligned}
$$

where CLIM\# is the climatology in question and CLIM1 is the reference climatology. Note that for CLIM2_GW and CLIM3_GW the reference climatologies are CLIM2 and CLIM3, respectively. 


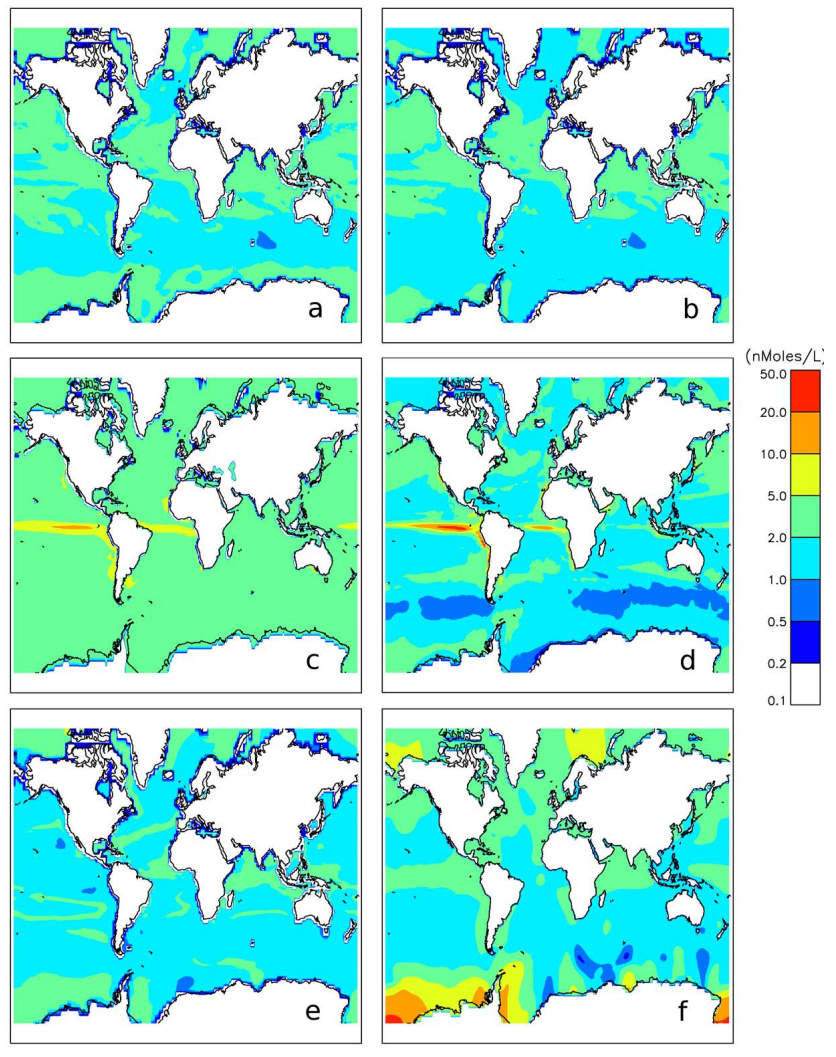

Fig. 1. The annual average sea-surface DMS concentration fields for the six present day climatologies in this study. They are (a) CLIM2 Simó and Dachs (2002) in PlankTOM5, (b) CLIM3 Vallina and Simó (2007) in PlankTOM5, (c) CLIM4 Anderson et al. (2001) in Diat-HadOCC (d) CLIM5 Simó and Dachs (2002) in Diat-HadOCC, (e) CLIM6 Vogt et al. (2009) in PlankTOM5. The reference Kettle and Andreae (2000) observational climatology (CLIM1) is shown in (f).

\section{Results and discussion}

\subsection{DMS fluxes}

The annual mean flux of DMS to the atmosphere predicted in the baseline simulation (CLIM1) is shown in Fig. 2. The peaks in emission conform generally to the areas of high seasurface DMS concentration in Fig. 1f. High wind speeds can also generate large fluxes even where the DMS surface concentration is relatively low, such as in the latitude band around $50^{\circ} \mathrm{S}$.

Figure 3 shows global maps of the absolute difference in annual mean DMS flux for each of the five climatologies compared to CLIM1. Annual mean global DMS fluxes range between 15.1 and $32.3 \mathrm{Tg} \mathrm{a}^{-1}$ sulphur (Table 1). The CLIM4 simulation stands out as predicting significantly higher DMS emissions (32.3 $\mathrm{Tg} \mathrm{a}^{-1}$ sulphur) than the other climatologies, the next largest being $19.4 \mathrm{Tg} \mathrm{a}^{-1}$ sulphur from CLIM5 (Ta-

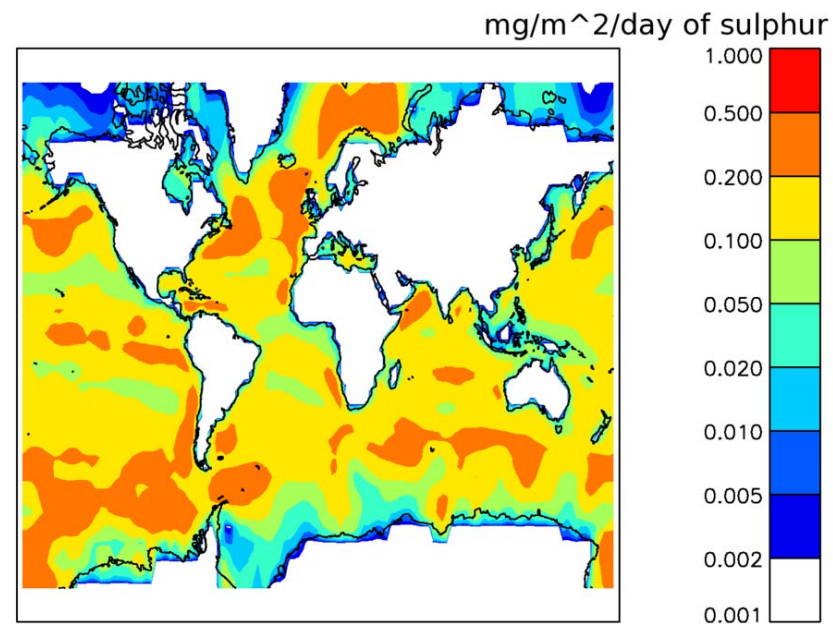

Fig. 2. The annual mean DMS flux calculated from the Kettle and Andreae (2000) climatology (CLIM1).

ble 1). The high flux in CLIM4 is a result of a minimum seawater DMS concentration $(2.29 \mathrm{nM})$ being prescribed in the Anderson et al. (2001) parameterisation. The other climatologies do not have this minimum value specified, and have large areas where seawater DMS concentration is below $1 \mathrm{nM}$.

Our calculated annual mean DMS fluxes (excluding CLIM4) are lower than the $24-27 \mathrm{Tg} \mathrm{a}^{-1}$ sulphur calculated by Boucher et al. (2003) and $28 \mathrm{Tg} \mathrm{a}^{-1}$ sulphur in Kloster et al. (2006). Boucher et al. (2003) calculate an annual DMS flux of $26.8 \mathrm{Tg} \mathrm{a}^{-1}$ sulphur when using the Kettle and Andreae (2000) DMS climatology and Nightingale et al. (2000) flux parameterisation, compared to the $18.6 \mathrm{Tg} \mathrm{a}^{-1}$ sulphur in the CLIM1 simulation here. The difference in calculated DMS flux must arise from the different wind speeds and assumed sea-surface temperatures used in the two models. The AEROCOM recommended flux is $18.2 \mathrm{Tg} \mathrm{a}^{-1}$ sulphur (Dentener et al., 2006). Flux uncertainty is increased further when different sea-air flux parameterisations are used (not investigated in this study). For example, Kettle and Andreae (2000) obtained a global flux of between 15 and $33 \mathrm{Tg} \mathrm{a}^{-1}$ sulphur using three parameterisations (Liss and Merlivat, 1986; Wanninkhof, 1992; Erickson, 1993), and Aumont et al. (2002) obtained fluxes between 17 and $26.7 \mathrm{Tg} \mathrm{a}^{-1}$ sulphur (using Liss and Merlivat, 1986; Wanninkhof, 1992). The variability in DMS emissions from the DMS climatologies tested here is similar to the variability from using different air-sea flux parameterisations.

Figure 4 summarises absolute differences in DMS flux and CCN concentration for June, December, and as an annual mean (see Sect. 3.5) for CLIM2-6 relative to CLIM1. In June, all the climatologies have lower DMS flux than CLIM1 at northern high latitudes and higher flux at lower latitudes. Climatologies 2,3 and 6 have lower fluxes than CLIM1 in the 


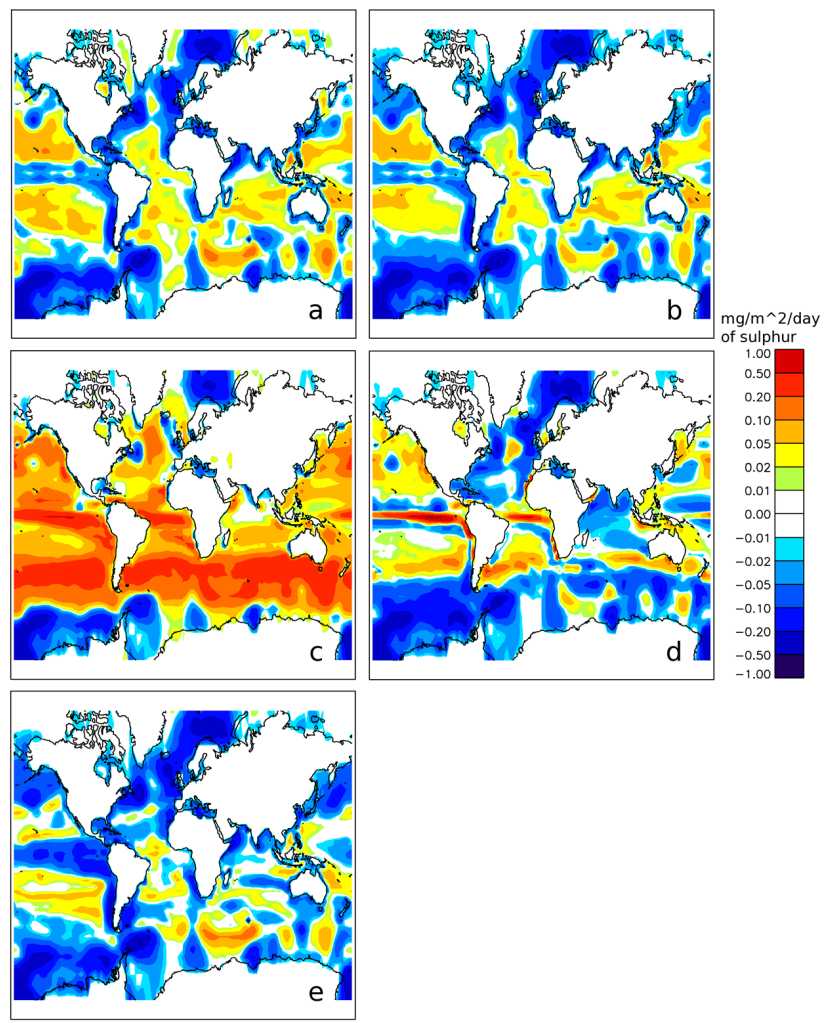

Fig. 3. Difference in DMS flux relative to the Kettle and Andreae (2000) climatology (CLIM1) for (a) CLIM2 Simó and Dachs (2002) in PlankTOM5, (b) CLIM3 Vallina and Simó (2007) in PlankTOM5, (c) CLIM4 Anderson et al. (2001) in Diat-HadOCC (d) CLIM5 Simó and Dachs (2002) in Diat-HadOCC, (e) CLIM6 Vogt et al. (2009) in PlankTOM5. Differences in DMS flux are also summarised in Fig. 4.

Northern Hemisphere (NH) (mean across CLIM2-6 - 19\%). The Southern Hemisphere (SH) DMS flux differences are all positive $($ mean $+39 \%)$ in June.

In December, climatologies 2, 4 and 5 produce higher DMS fluxes than CLIM1 in the NH (mean $+8 \%$ ), and all but CLIM4 produce lower fluxes in the SH (mean -32\%).

The annual global mean DMS fluxes lie between $14.4 \%$ lower to $74.7 \%$ higher than CLIM1, with two climatologies (CLIM3 and CLIM6) being lower and three higher (CLIM2, 4 and 5).

A feature shared by all five simulations compared to CLIM1 is the lower annual mean flux from high latitudes $\left(>60^{\circ} \mathrm{N}\right.$ or S)(Fig. 3). The DMS climatologies tested here show some seasonality in the seawater DMS concentrations and hence fluxes, with higher concentrations in the summer than winter (not shown). The lower fluxes at high latitudes in CLIM2-6 are possibly the result of the sampling bias in the observational climatology CLIM1 (Kettle and Andreae, 2000), mentioned in Sect. 1. Fluxes during the summer months at high latitudes are considerably higher than dur- ing winter. It is notable that the model climatologies generally show higher DMS flux compared to CLIM1 in the winter hemispheres, and lower DMS flux in the summer hemispheres. The CLIM4 simulation (Fig. 3c) has higher fluxes in the summer hemispheres also, despite the lower flux at higher latitudes. CLIM4 global annual mean DMS flux is $42 \%$ higher than CLIM1.

\subsection{Comparison with atmospheric DMS observations}

Figure 5 compares monthly mean atmospheric DMS concentrations from the six climatologies against long term (>1 year) observations from three sites: Amsterdam Island (southern Indian Ocean, $37^{\circ} 50^{\prime} \mathrm{S}, 77^{\circ} 35^{\prime} \mathrm{E}$, Jourdain and Legrand, 2001), Dumont d'Urville (Antarctica, 66 $40^{\prime} \mathrm{S}$, $140^{\circ} 1^{\prime}$ E, Nguyen et al., 1992), and Cape Grim (Tasmania, $40^{\circ} 41^{\prime} \mathrm{S}, 144^{\circ} 41^{\prime} \mathrm{E}$, Ayers et al., 1991).

The agreement between the different models and the observations is generally good, with the normalised annual mean bias ([model-observation]/observation averaged over the 3 sites) for 5 of the climatologies (excluding CLIM4) lying between -0.02 (CLIM1) and -0.22 (CLIM6). The CLIM4 mean bias was up to 1.46 at Cape Grim. The CLIM4 climatology is consistently higher at Amsterdam Island and Cape Grim, confirming the findings of Belviso et al. (2004b) that DMS fluxes and (hence seawater concentrations) from Anderson et al. (2001) are too high. A clear seasonal cycle can be seen in the model simulations and observations with higher DMS in summer months. Calculated values of root mean square deviation (RMSD) are between $30 \mathrm{ppt}$ and $85 \mathrm{ppt}$ for 5 of the climatologies; CLIM4 has an RMSD of up to $203 \mathrm{ppt}$ at Amsterdam Island. The ratio of winter to summer (DJF/JJA) DMS observations at Amsterdam Island and Cape Grim is 4.4 and 5.9, respectively. The models range between 3.0 and 5.9 at Amsterdam Island, and 3.1 and 7.5 at Cape Grim.

The interannual variabilitiy of DMS fluxes (which exert a strong influence on atmospheric DMS concentrations) is discussed in Sect. 3.7. The mean interannual variability of atmospheric DMS concentrations between the years 1999 and 2001 is also calculated, and found to be up to $\sim 29 \%, \sim 8 \%$, and $\sim 7 \%$ for Cape Grim, Amsterdam Island and Dumont d'Urville, respectively.

\subsection{Contribution of DMS to $\mathrm{CCN}$}

Figure 6a shows a global map of simulated surface level annual mean CCN concentrations for CLIM1. CCN are defined here to be soluble particles with equivalent dry radii greater than $35 \mathrm{~nm}$, appropriate for a supersaturation of $\sim 0.23 \%$. $\mathrm{CCN}$ concentrations are given at ambient conditions. High concentrations of $\mathrm{CCN}$ are coincident with strong anthropogenic sources (e.g. China, North America and Europe), and terrestrial biogenic sources (sub-Saharan Africa, South 

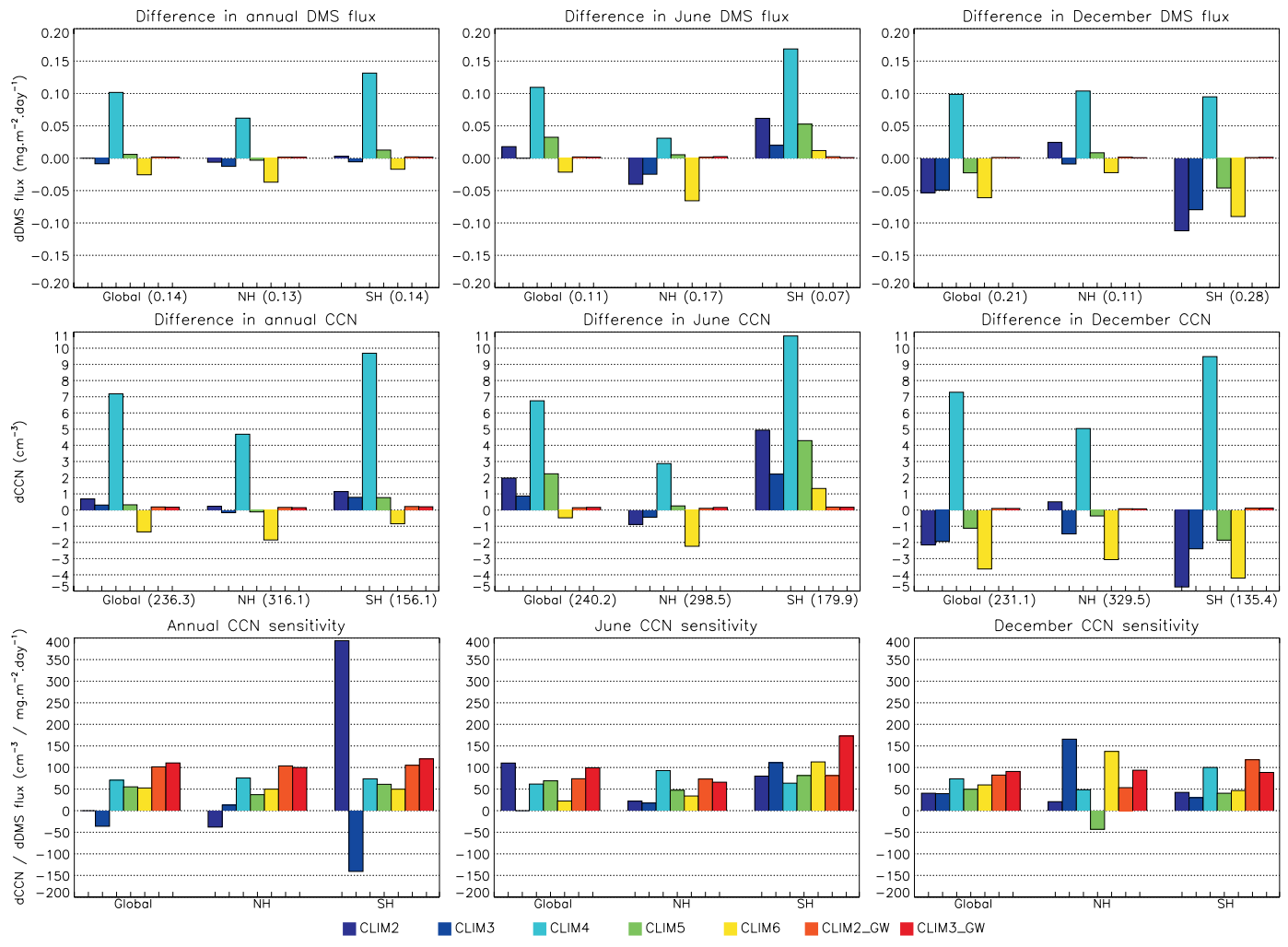

Fig. 4. Annual, June, and December mean absolute difference of DMS flux (in $\mathrm{mg} \mathrm{m}^{-2} \mathrm{day}^{-1}$ sulphur), concentration of CCN (number/ $\mathrm{cm}^{3}$ ) $>35 \mathrm{~nm}$ dry radius at the surface, and absolute CCN sensitivity for the five present day climatologies, relative to CLIM1 with the Kettle and Andreae (2000) climatology, and for the GW scenarios relative to CLIM2 and CLIM3. DMS flux differences are ocean only, i.e. land areas are not included in the calculation of DMS fluxes. CCN values are an average over all areas. Numbers in brackets are global, NH and SH means for the CLIM1 control.

America). The simulation predicts low $\mathrm{CCN}$ concentrations over the high latitude southern oceans.

The annual mean contribution of DMS to CCN is shown in Fig. 6b, calculated by subtracting a simulation with no DMS emissions from CLIM1. The largest contribution is close to land in the tropics (up to $50 \mathrm{CCN} \mathrm{cm}^{-3}$ ). This region has some of the highest DMS emissions (Fig. 2, up to $5 \times 10^{-1} \mathrm{mg} / \mathrm{m}^{2} /$ day sulphur), but also other large sources of $\mathrm{CCN}$. Over remote ocean areas, the contribution to $\mathrm{CCN}$ is approximately $5-10 \mathrm{CCN} \mathrm{cm}^{-3}$.

Figure $6 \mathrm{c}$ shows that the largest fractional contribution of DMS to CCN (excluding Antarctica) is in the SH midlatitudes $(>20 \%)$, but less than $1 \%$ in regions with strong anthropogenic sources. This result is consistent with the findings of Korhonen et al. (2008). We calculate that the annual mean contribution of DMS to CCN in the $\mathrm{NH}$ is 3.3\%, compared to $9.9 \%$ in the SH. Figure 6 also illustrates that the influence of DMS on CCN is not limited to the oceans, due to the timescales for $\mathrm{CCN}$ production, discussed further below.

\subsection{Contribution of sub-micron sea spray to $\mathrm{CCN}$}

We have previously compared the sectional version of GLOMAP against CCN measurements from Cape Grim using the Kettle and Andreae (2000) DMS climatology (Korhonen et al., 2008), reproducing the seasonal cycle and absolute values of CCN well. Figure 7 shows a comparison of CCN observations from Cape Grim (Ayers and Gras, 1991) against the sectional version of GLOMAP from Korhonen et al. (2008) and CLIM1 from this study. The results of Korhonen et al. (2008) show a higher baseline CCN concentration than CLIM1 (annual mean difference $\sim 50 \mathrm{~cm}^{-3}$ ). Differences up to a factor of four are also evident over the Southern Ocean (not shown). This difference can be explained by the lack of ultrafine sea spray emissions in the simulations here. Korhonen et al. (2008) use the Mårtensson et al. (2003) laboratory derived parameterisation, which includes emissions in the sub-micron size range. Sea spray emissions at this size range are quite uncertain however. Figure 7 also shows simulations with no DMS emissions. This study is concerned with the absolute difference in CCN resulting from altered DMS emissions. In the summer months $\triangle \mathrm{CCN}$ ("with DMS" 

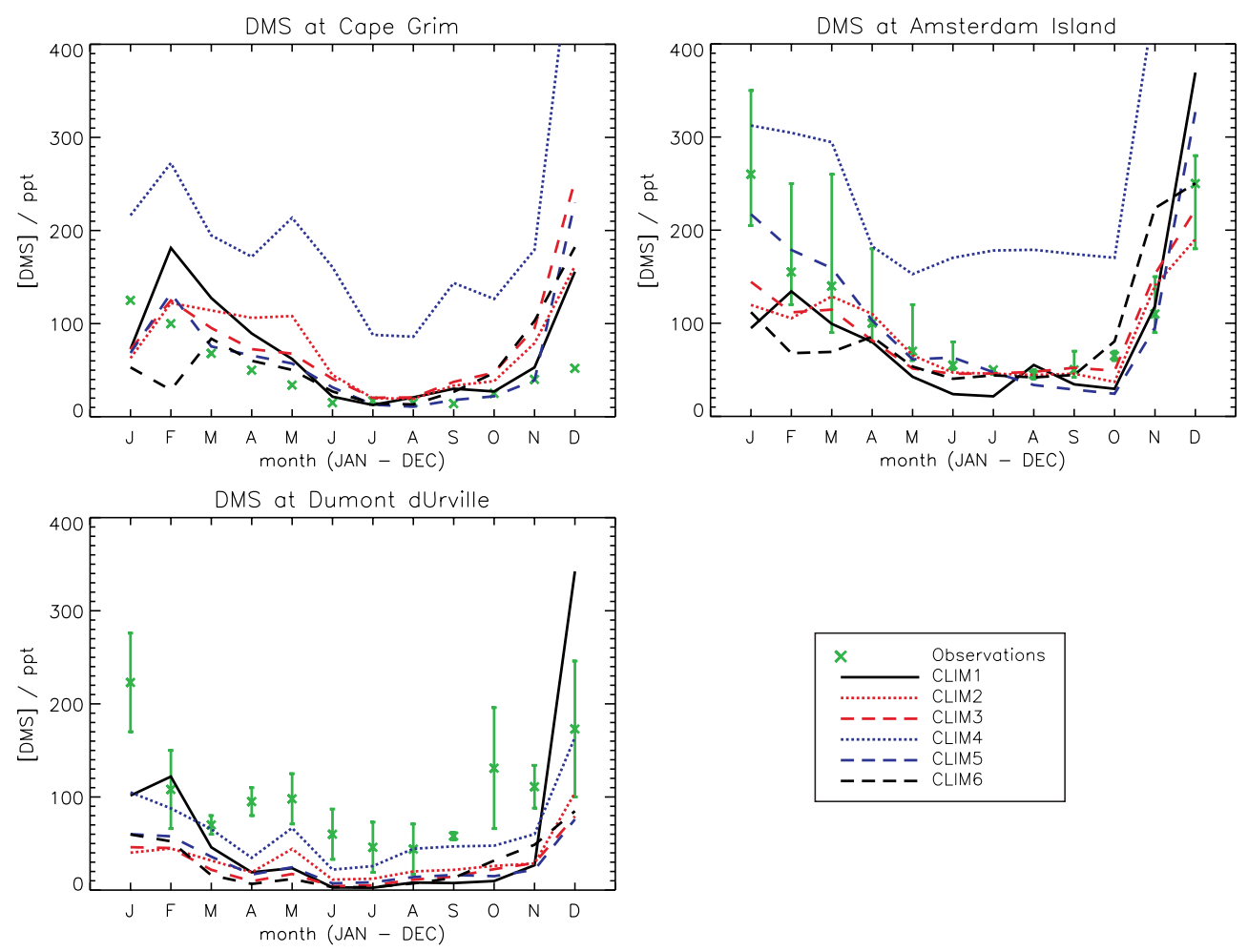

Fig. 5. Predicted atmospheric DMS concentrations from the five present day climatologies, plotted against monthly averaged observations from three sites, Cape Grim, Amsterdam Island and Dumont d'Urville. Observations show error bars where known (Amsterdam Island: 5th and 95th percentiles; Dumont d'Urville: \pm 1 standard deviation).
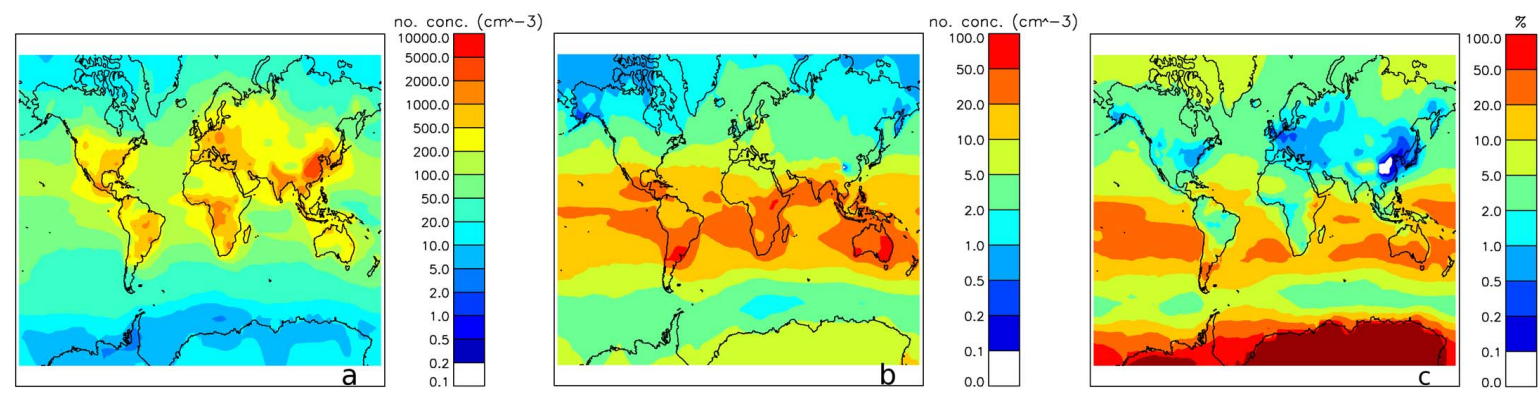

Fig. 6. (a) The annual average $\mathrm{CCN}>35 \mathrm{~nm}$ dry radius number concentration at the surface, calculated from the Kettle and Andreae (2000) climatology (CLIM1). (b) The difference in CCN between a simulation with no DMS and CLIM1, i.e. the absolute contribution of DMS to CCN. (c) The fractional contribution of DMS to CCN.

minus "without DMS") in Korhonen et al. (2008) is similar to $\triangle \mathrm{CCN}$ presented here, generally within a few $\mathrm{CCN} \mathrm{cm}^{-3}$ (Fig. 7). In the winter months, Korhonen et al. (2008) described an inverse CLAW effect, where CCN concentrations increased when DMS emissions were turned off. This effect is not seen in the present results, possibly due to the lack of ultrafine sea spray emissions.

\subsection{Sensitivity of CCN to DMS climatology}

Figure 4 summarises annual, June and December differences in DMS and CCN concentrations for the five climatologies. To compare how CCN concentrations depend on the climatology used we calculate mean values of absolute $\mathrm{CCN}$ sensitivity: 

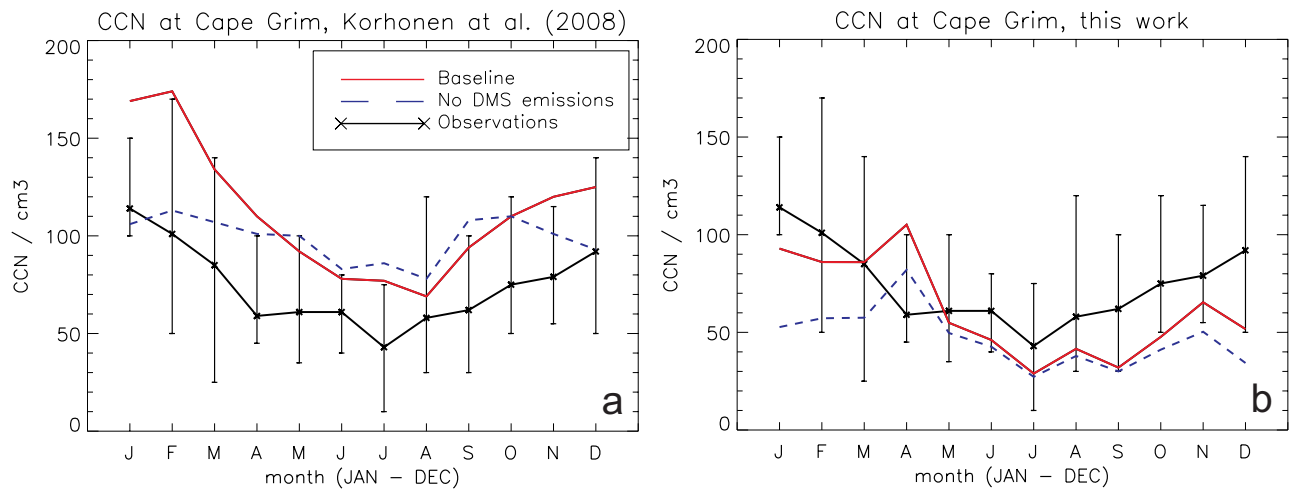

Fig. 7. Comparison of CCN from two GLOMAP model runs with and without DMS emissions, against observations from Cape Grim (Ayers and Gras, 1991), (a) from Korhonen et al. (2008), with sub-micron sea spray emissions, (b) from this study, without sub-micron sea spray emissions. Error bars show the range of monthly median values for the years 1981 to 1989 from the CCN observations.

Absolute CCN Sensitivity $=\Delta \mathrm{CCN}_{\mathrm{abs}} / \Delta$ Flux $_{\mathrm{DMS}, \text { abs }}$

In the $\mathrm{SH}$ summer all the climatologies except CLIM4 produce less DMS than CLIM1 (December mean difference $0.082 \mathrm{mg} \mathrm{m}^{-2} \mathrm{day}^{-1}$ sulphur or $43 \%$ less), which results in slightly lower mean $\mathrm{CCN}$ concentrations $\left(-3.3 \mathrm{~cm}^{-3}\right)$. The reverse is true in the SH winter (June), with all climatologies producing more DMS and consequently more CCN. June and December hemispheric mean absolute $\mathrm{CCN}$ sensitivities range from -43 to $166 \mathrm{~cm}^{-3} /\left(\mathrm{mg} \mathrm{m}^{-2} \mathrm{day}^{-1}\right.$ sulphur $)$ using the present day climatologies, with a mean of $63 \mathrm{~cm}^{-3} /\left(\mathrm{mg} \mathrm{m}^{-2}\right.$ day $^{-1}$ sulphur). The mean absolute $\mathrm{CCN}$ sensitivity in the $\mathrm{SH}$ summer is $52 \mathrm{~cm}^{-3} /\left(\mathrm{mg} \mathrm{m}^{-2} \mathrm{day}^{-1}\right.$ sulphur) and varies between 30 (CLIM3) and $100 \mathrm{~cm}^{-3} /\left(\mathrm{mg} \mathrm{m}^{-2} \mathrm{day}^{-1}\right.$ sulphur) (CLIM4), although CLIM2, 5 and 6 are in the range 40 to $47 \mathrm{~cm}^{-3} /\left(\mathrm{mg} \mathrm{m}^{-2}\right.$ day $^{-1}$ sulphur $)$. The absolute CCN sensitivity in the $\mathrm{NH}$ summer is slightly lower than the $\mathrm{SH}$ summer, with a mean of $43 \mathrm{~cm}^{-3} /\left(\mathrm{mg} \mathrm{m}^{-2} \mathrm{day}^{-1}\right.$ sulphur). The winter hemisphere $\mathrm{CCN}$ concentrations are more sensitive to DMS than the respective summer hemispheres: winter hemisphere mean $78 \mathrm{~cm}^{-3} /\left(\mathrm{mg} \mathrm{m}^{-2} \mathrm{day}^{-1}\right.$ sulphur $)$ versus summer hemisphere mean $47 \mathrm{~cm}^{-3} /\left(\mathrm{mg} \mathrm{m}^{-2}\right.$ day $^{-1}$ sulphur), although relative differences in the winter hemisphere marine regions are much less important because of the higher sea spray-derived CCN.

The differences in the hemispheric mean values of absolute $\mathrm{CCN}$ sensitivity between the five climatologies shows that $\mathrm{CCN}$ production is dependent not only on the magnitude of the mean DMS flux, but also on the spatial distribution of the emissions. The spatial distribution of the $\mathrm{CCN}$ difference field (CLIM2 to CLIM5 minus CLIM1) are shown in Fig. 8. The largest positive differences are for CLIM4 (Fig. 8c) and reach $\sim 20 \mathrm{~cm}^{-3} /\left(\mathrm{mg} \mathrm{m}^{-2}\right.$ day $^{-1}$ sulphur) at high latitudes. Comparison of Fig. 3 and Fig. 8 shows that an increase in DMS flux in one region does not always cause a collocated increase in CCN. Differences in oxidant concentrations
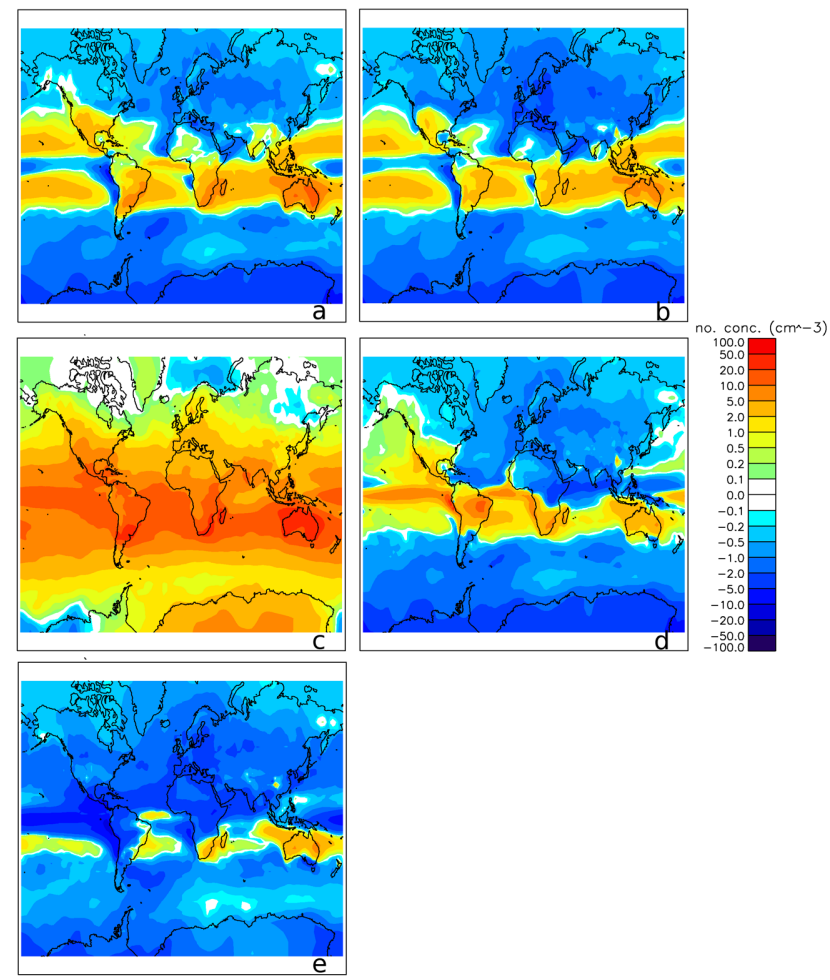

Fig. 8. Annual average difference in CCN concentrations (>35 nm dry radius) at the surface for the different climatologies compared to the Kettle and Andreae (2000) climatology. (a) CLIM2 Simó and Dachs (2002) in PlankTOM5, (b) CLIM3 Vallina and Simó (2007) in PlankTOM5, (c) CLIM4 Anderson et al. (2001) in Diat-HadOCC (d) CLIM5 Simó and Dachs (2002) in Diat-HadOCC, (e) CLIM6 Vogt et al. (2009) in PlankTOM5. 
between regions strongly affect the potential of the DMS to make new aerosol. Also the production of new DMS-derived $\mathrm{CCN}$ can take several days depending on season and latitude. During this time, the DMS, its oxidation products and the extra nucleated particles are transported large distances, hence DMS impacts on aerosol are strongly non-local. Such longdistance impacts were illustrated in Woodhouse et al. (2008) by studying $\mathrm{CCN}$ production from a small patch with increased DMS emission. Figures 3 and 8 also show that large areas experience decreased $\mathrm{CCN}$ concentrations in response to a higher DMS flux since existing aerosol can grow to sizes where they are more susceptible to removal by precipitation, leading to fewer CCN. This was also described in Korhonen et al. (2008), and termed 'inverse CLAW'. The large regional variations in CCN response to differences in DMS flux explains why hemispheric mean values of absolute $\mathrm{CCN}$ sensitivity vary between 43 and $90 \mathrm{~cm}^{-3} /\left(\mathrm{mg} \mathrm{m}^{-2}\right.$ day $^{-1}$ sulphur).

Figure 4 shows that one global and three hemispheric mean $\mathrm{CCN}$ sensitivities are negative. A combination of factors causes this. The efficiency of conversion of DMS to $\mathrm{CCN}$ is not expected to be spatially homogeneous (for the reasons discussed above). Additionally, DMS flux differences (Fig. 3) are spatially inhomogeneous. For example, if a large localised decrease in DMS flux relative to CLIM1 coincides with an area where DMS to CCN conversion is inefficient, there will be only a small decrease in CCN number concentration. Likewise, small decreases in DMS flux elsewhere can result in large increases in CCN. The net effect of these spatial differences in $\mathrm{CCN}$ production can result in a negative value of $\mathrm{CCN}$ sensitivity on a hemispheric mean.

The absolute CCN sensitivities, while simplest to interpret, do not take account of the background concentrations of CCN from other sources, such as sea spray and anthropogenic emissions. Small absolute differences in $\mathrm{CCN}$ may be very important for climate in remote regions, but much less important in polluted regions. We therefore calculate values of relative $\mathrm{CCN}$ sensitivity:

Relative CCN Sensitivity $=\frac{\Delta \mathrm{CCN}_{\text {rel }}}{\Delta \text { Flux }_{\mathrm{DMS}, \text { rel }}}$

To calculate relative $\mathrm{CCN}$ sensitivities between climatologies, $\mathrm{CCN}$ contributions from sub-micron sea spray are taken into account, which were not included in the simulations presented so far. To do that we used existing simulations from GLOMAP-bin (sectional version of GLOMAP) where we separated out the contribution of ultrafine sea spray to $\mathrm{CCN}$. These CCN concentration fields were added to the $\mathrm{CCN}$ values calculated by GLOMAP-mode above. Including the ultrafine sea spray contribution to $\mathrm{CCN}$ offline from the model is a valid step. Merikanto et al. (2009) show that the flux of aerosol number into the marine boundary layer from the free troposphere is not affected by primary particles emitted at the surface, and that the free troposphere is the main source of
DMS-derived CCN. This suggests that the free-tropospheric aerosol and sea spray are effectively decoupled.

Figure 9 shows June and December relative sensitivities. The mean June and December hemispheric relative sensitivity is 0.02 (range -0.01 to 0.06 ) for the $\mathrm{NH}$ and 0.07 (range 0.04 to 0.22 ) for the $\mathrm{SH}$. This shows the greater sensitivity of CCN concentrations in the SH to differences in flux of DMS, principally because of the lower background concentrations of aerosol in the SH. The combined June and December hemispheric mean is 0.05 .

\subsection{Globally warmed climatologies}

The globally warmed seawater DMS fields (CLIM2_GW and CLIM3_GW) and the associated present day fields (CLIM2 and CLIM3) are described in Vallina et al. (2007). Two different parameterisations derive the DMS concentration, calculated in the OPA-ORCA-LIM ocean GCM. The ocean model is forced by National Centers for Environmental Protection-National Center for Atmospheric Research (NCEP-NCAR) meteorological re-analysis fields (Kistler et al., 2001). The atmospheric global warming scenario was obtained from forcing changes from the IPSL (Institut PierreSimone Laplace) model using the Intergovernmental Panel on Climate Change scenario A2 (Friedlingstein et al., 2001).

The higher DMS sea water concentrations in CLIM2_GW and CLIM3_GW give rise to small but similar increases in global annual mean DMS flux $(\sim 1 \%$, or $<0.002 \mathrm{mg} \mathrm{m}^{-2} \mathrm{day}^{-1}, 0.2 \mathrm{Tg} \mathrm{a}^{-1}$ sulphur, Fig. 10) and $\mathrm{CCN}$ concentration $\left(\sim 0.2 \mathrm{CCN} \mathrm{cm}^{-3}, 0.07 \%\right)$, with larger local differences of $\pm 20 \%$ in DMS flux and $\pm 1 \%$ in CCN. The largest mean hemispheric difference in DMS flux occurs in the SH (Fig. 4, Fig. 10a and b), while the largest absolute difference in $\mathrm{CCN}$ of $\sim 1.0 \mathrm{~cm}^{-3}$ occurs in the tropics. In relative terms the biggest $\mathrm{CCN}$ response is over the $\mathrm{SH}$ where background $\mathrm{CCN}$ concentrations are low, but even here the increase in $\mathrm{CCN}$ is less than a few tenths of a percent (mean $0.1 \%)$.

A reduction of the MLD in the global warming scenario is responsible for the increases in seawater DMS concentration (Vallina et al., 2007). The increases are comparable to those predicted by Bopp et al. (2004) using a coupled ocean-atmosphere model with an empirical planktonseawater DMS relationship. In contrast, Kloster et al. (2007) calculated a $\sim 10 \%$ reduction in global mean DMS flux to the atmosphere in their future scenario due to decreased seawater DMS concentrations in a coupled ocean-atmosphere model with a mechanistic representation of DMS production. The decreased seawater DMS concentrations resulted primarily from increases in MLD in the Southern Ocean. There is therefore considerable uncertainty in the response of seawater DMS concentrations to global warming.

The global annual mean absolute and relative differences in DMS and CCN resulting from the global warming scenario compared to the present day are smaller than those for 

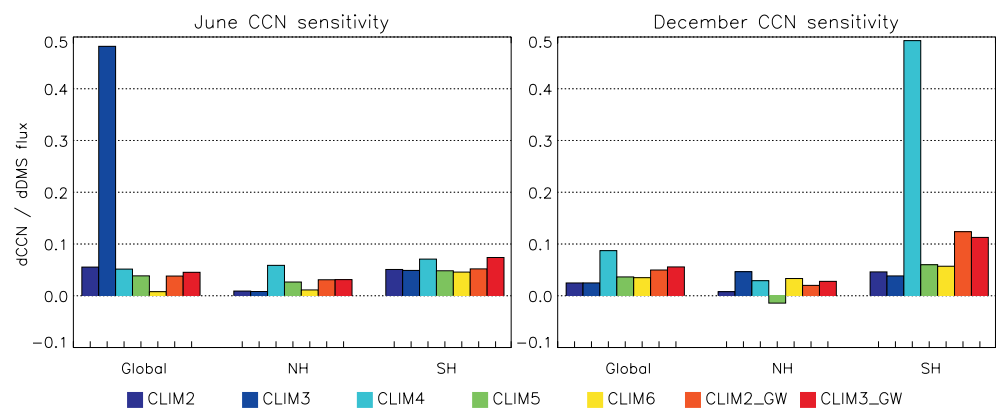

Fig. 9. June, and December relative CCN sensitivities for the five present day climatologies, relative to CLIM1 with the Kettle and Andreae (2000) climatology, and for the GW scenarios relative to CLIM2 and CLIM3.
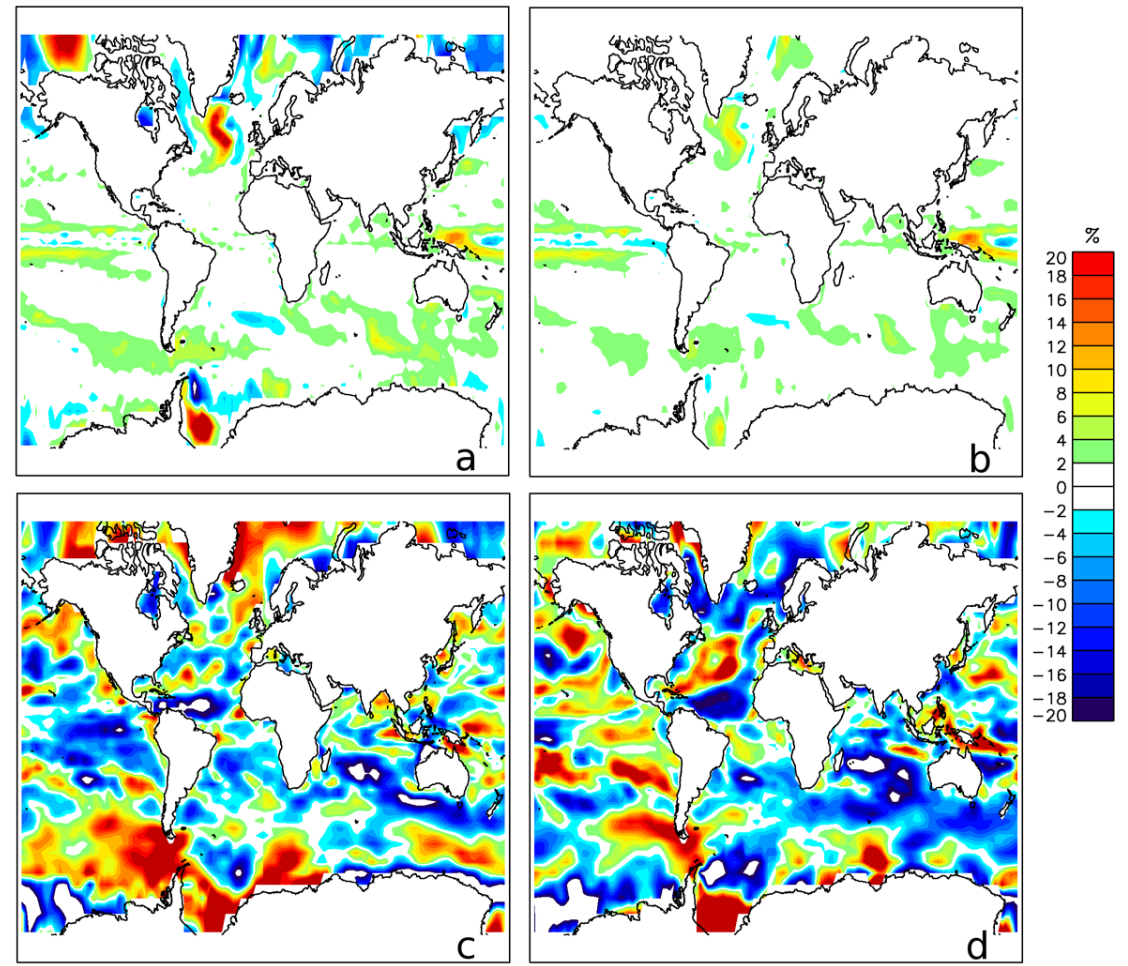

Fig. 10. Annual mean relative change in DMS emissions for (a) CLIM2_GW, (b) CLIM3_GW (with respect to CLIM2 and CLIM3), (c) CLIM1_1999, and (d) CLIM1_2001 (both with respect to CLIM1).

the present day climatologies CLIM2 and CLIM3 (Fig. 4) compared to CLIM1. Absolute hemispheric June and December $\mathrm{CCN}$ sensitivities from the $\mathrm{GW}$ scenarios range from 53 to $173 \mathrm{~cm}^{-3} /\left(\mathrm{mg} \mathrm{m}^{-2} \mathrm{day}^{-1}\right.$ sulphur) with a mean of $93 \mathrm{~cm}^{-3} /\left(\mathrm{mg} \mathrm{m}^{-2} \mathrm{day}^{-1}\right.$ sulphur). Relative hemispheric June and December sensitivities (Fig. 9) range from 0.02 to 0.12 with a mean of 0.06 . These compare well with the sensitivities calculated for the present day climatologies, suggesting that the sensitivities are robust over a range of scenarios. Assuming that the global relative $\mathrm{CCN}$ sensitivity is 0.06 , it is possible to estimate that the $\sim 10 \%$ global re- duction in DMS flux to the atmosphere predicted by Kloster et al. (2007) would result in a $0.6 \%$ decrease in the global mean surface level CCN concentration in our model. By contrast, Bopp et al. (2004) predict a 3\% increase in DMS flux, which translates into a $0.2 \%$ increase in CCN. A global mean DMS flux increase of $>160 \%$ would be required to give a $10 \%$ increase in CCN concentration. These estimates do not account for differences in atmospheric conditions as a result of global warming that may also affect the sulphur cycle in the atmosphere. 


\subsection{Interannual variability}

The "meteorological year" (for wind speeds etc) used in the previous experiments was 2000, in order to keep wind speeds consistent between simulations. The effect of using different meteorological years on DMS flux and CCN is investigated here by re-running the CLIM1 simulations for 1999 and 2001. The annual mean DMS flux decreased by $0.002 \mathrm{mg} \mathrm{m}^{-2} \mathrm{day}^{-1}$ sulphur (1.2\%) in 1999 and by $0.001 \mathrm{mg} \mathrm{m}^{-2} \mathrm{day}^{-1}$ sulphur (1.1\%) in 2001, from that predicted for 2000, and therefore very similar to the change predicted in the global warming scenarios in Sect. 3.6. The total DMS emission varies from 18.4 to $18.6 \mathrm{Tg} \mathrm{a}^{-1}$ sulphur between CLIM1_1999 and CLIM1 (Table 1). A notable aspect of these interannual simulations is that the spatial variability of annual mean DMS flux is much larger than between the globally warmed and present day simulations, suggesting that regional changes in $\mathrm{CCN}$ might be larger still than global changes.

\subsection{Implications for the CLAW hypothesis}

The increase in global annual mean DMS flux from the global warming scenario is similar in magnitude to that resulting from interannual variability of wind speed $\left(\sim 0.2 \mathrm{Tg} \mathrm{a}^{-1}\right.$ sulphur) (Table 1). The CLAW hypothesis requires a strong link between climate and DMS flux (via aerosol). The global warming scenarios tested here suggest that future changes in DMS flux are likely to be very small, with negligible subsequent impacts on $\mathrm{CCN}$ concentrations. The low sensitivity of CCN to changes in DMS flux, coupled with the small predicted increases in DMS flux under global warming conditions, suggest that the CLAW feedback is therefore probably unimportant in modern day climate change.

However, the simulations in this study focus only on differences in DMS seawater concentrations, so any feedback involving winds is not represented. Bopp et al. (2004) found that increases in wind speed under a global warming scenario amplify DMS emissions by $0.46 \mathrm{Tg} \mathrm{a}^{-1}$ sulphur, compared to an increase of $0.30 \mathrm{Tg} \mathrm{a}^{-1}$ sulphur resulting from differences in seawater DMS concentration alone. Long term observations have shown patterns of regional change (both increases and decreases) in marine wind speeds, but no significant global trend (Trenberth et al., 2007) over recent decades. This study does not rule out the possibility of regional changes in wind speed leading to significantly altered DMS emissions. Wind speed is particularly important in DMS emission (and also sea spray emission) due to the non-linear (square or cubic) relationship between piston velocity and wind speed. Small differences in seawater DMS in areas with high wind speeds can therefore result in significant differences in DMS flux. Korhonen et al. (2010) showed that the increase in wind speed of $0.45 \pm 0.2 \mathrm{~ms}^{-1} \mathrm{decade}^{-1}$ at 50 $65^{\circ} \mathrm{S}$ since the early 1980 's caused a $22 \%$ increase in CCN concentrations at these latitudes. They found that changes in sea spray emissions were far more important than wind speed dependent changes in DMS flux. Furthermore, wind speed changes could also alter production of DMS in the surface ocean through impacts on the MLD. A fundamental property of the oceans, MLD can influence nutrient and sunlight availability, and hence DMS production (e.g. Vallina et al., 2007).

The globally warmed DMS fields used in this study are calculated using simple empirical relationships (see Vallina et al., 2007). A mechanistic model, that explicitly represents the processes that form and destroy DMS and the dynamics within a marine ecosystem, might respond differently to a global warming scenario. Changes in nutrient availability might also result from climate change, with a subsequent impact on phytoplankton production. The positive response of DMS to global warming is not certain however, Kloster et al. (2007) find a negative change in DMS as a result of climate change in a coupled atmosphere-ocean model.

\section{Conclusions}

Using a Global Model of Aerosol Processes (GLOMAP) with six different present day surface ocean DMS climatologies, and two climatologies calculated using global warming scenarios, the response of aerosol and $\mathrm{CCN}$ to changes in sea-air flux of DMS was calculated. Relative to a simulation with DMS seawater concentrations as in the Kettle and Andreae (2000) observational climatology, we calculate a hemispheric CCN sensitivity $\Delta \mathrm{CCN} / \Delta$ Flux $_{\mathrm{DMS}}$, to measure the response of the cloud nuclei population to calculated differences in sea-air DMS flux. The sensitivity was found to be relatively consistent between climatologies with mean absolute hemispheric sensitivities for June and December of $63 \mathrm{~cm}^{-3} /\left(\mathrm{mg} \mathrm{m}^{-2} \mathrm{day}^{-1}\right.$ sulphur) for present day and $93 \mathrm{~cm}^{-3} /\left(\mathrm{mg} \mathrm{m}^{-2} \mathrm{day}^{-1}\right.$ sulphur) for increased DMS fluxes under global warming scenarios. The relative $\mathrm{CCN}$ sensitivities (i.e. fractional change in $\mathrm{CCN}$ divided by fractional change in DMS flux) were 0.05 for present day and 0.06 for the global warming scenarios, suggesting that an increase in DMS flux of $>160 \%$ would be required to give an increase in $\mathrm{CCN}$ of $10 \%$.

Despite six different DMS climatologies producing a wide range of DMS fluxes, the modelled response on a global and hemispheric scale in the number of $\mathrm{CCN}$ is low, though the sensitivity could be higher in some regions. Very large changes in the flux of DMS to the atmosphere would therefore be required to have any significant effect on CCN.

Seawater DMS concentrations calculated in a model driven by a global warming scenario result in annual mean DMS flux increases of only $\sim 1 \%$. This is similar to the DMS flux differences resulting from interannual variation in wind speed. A low sensitivity between DMS and CCN, and the small changes in DMS concentration predicted under 
global warming scenarios, suggest that the CLAW feedback might be very weak, and not significant in present day climate change. It is not possible to discount regional DMS flux changes, e.g. as a result of wind speed changes, being significant however. Korhonen et al. (2010) calculate that locally up to $33 \%$ of $\mathrm{CCN}$ changes due to changes in wind speed could be due to higher DMS fluxes, with the rest being due to changes in sea spray.

This study also highlights the sensitivity of DMS production to the ocean biogeochemistry model used, and to the GCM it is embedded in. Simulations CLIM2 and CLIM5 both used the Simó and Dachs (2002) MLD empirical relationship to calculate sea-surface DMS, but in different marine ecosystem and physical models, PlankTOM5 in OPA-ORCA-LIM and Diat-HadOCC in HadGEM2, respectively. The two implementations produce quite different DMS fields, and hence fluxes. The driving ocean model would appear to be just as, or more important, than the DMS parameterisation.

Given the consensus among the model climatologies, and the reasons noted in the introduction, it is likely that the observational Kettle and Andreae (2000) climatology overestimates seawater DMS concentrations at the higher latitudes in summer, particularly in the Southern Ocean. It is not possible to establish which climatology is the best one to use when simulating present day climate, given the complexity of the system and the relatively few long term observations. The variability displayed by the model derived simulations shown here highlights the uncertainty within DMS producing models. This uncertainty is one of the problems in quantifying and understanding the CLAW feedback. Changes in DMS flux resulting from the global warming and interannual simulations are much less than the variability arising from using different models to calculate sea-surface DMS concentration. When the uncertainty associated with sea-air flux parameterisation is taken into consideration, the actual flux of DMS to the atmosphere is not accurately known.

There is the potential for further work using a more detailed DMS oxidation scheme using online oxidants, and including oxidation by $\mathrm{BrO}$ and other halogens. This could lead to a shift in the pathways DMS goes down to form CCN, and potentially impact the calculated sensitivities.

This study has concentrated on hemispheric and global changes. Given that $\mathrm{CCN}$ production potential and removal efficiency is spatially variable, and that regional differences in background $\mathrm{CCN}$ will affect the relative impact of DMS on $\mathrm{CCN}$, further simulations are planned to investigate the regional sensitivities of CCN to DMS. Additionally, it is known that DMS flux is very sensitive to wind speed. Regional increases (and decreases) in wind speed may be significant under global warming scenarios, with subsequent impacts on DMS flux and CCN, and should be investigated further.
Acknowledgements. We thank Jeff Pierce and Roland von Glasow for their thorough and helpful comments on the manuscript. MTW was funded by a NERC UK-SOLAS CASE studentship with the UK Met Office, and thanks Steven J Pickering for his effort with GLOMAP, Hannele Korhonen for data and discussion, Joonas Merikanto for ultrafine CCN contributions, and Tom Breider for chemistry discussion. The work of OB was supported by the Joint DECC and Defra Integrated Climate Programme DECC/Defra (GA01101). GWM is an NCAS funded Research Fellow.

Edited by: J. Quaas

\section{References}

Anderson, T. R., Spall, S. A., Yool, A., Cipollini, P., Challenor, P. G., and Fasham, M. J. R.: Global fields of sea surface dimethylsulfide predicted from chlorophyll, nutrients and light, J. Marine Syst., 30, 1-20, 2001.

Aranami, K. and Tsunogai, S.: Seasonal and regional comparison of oceanic and atmospheric dimethylsulfide in the northern North Pacific: Dilution effects on its concentration during winter, J. Geophys. Res.-Atmos., 109, D12303, doi:10.1029/2003JD004288, 2004.

Aumont, O., Belviso, S., and Monfray, P.: Dimethylsulfoniopropionate (DMSP) and dimethylsulfide (DMS) sea surface distributions simulated from a global three-dimensional ocean carbon cycle model, J. Geophys. Res.-Oceans, 107, 3029, doi:10.1029/1999JC000111, 2002.

Ayers, G. P. and Cainey, J. M.: The CLAW hypothesis: a review of the major developments, Environ. Chem., 4, 366-374, 2007.

Ayers, G. P. and Gras, J. L.: Seasonal Relationship Between Cloud Condensation Nuclei and Aerosol Methanesulfonate In Marine Air, Nature, 353, 834-835, 1991.

Ayers, G. P., Ivey, J. P., and Gillett, R. W.: Coherence Between Seasonal Cycles Of Dimethyl Sulfide, Methanesulfonate And Sulfate In Marine Air, Nature, 349, 404-406, 1991.

Barnes, I., Hjorth, J., and Mihalopoulos, N.: Dimethyl sulfide and dimethyl sulfoxide and their oxidation in the atmosphere, Chem. Rev., 106, 940-975, 2006.

Bates, T. S., Cline, J. D., Gammon, R. H., and Kelly-Hansen, S. R.: Regional And Seasonal-Variations In The Flux Of Oceanic Dimethylsulfide To The Atmosphere, J. Geophys. Res.-Oceans, 92, 2930-2938, 1987.

Belviso, S., Bopp, L., Moulin, C., Orr, J. C., Anderson, T. R., Aumont, O., Chu, S., Elliott, S., Maltrud, M. E., and Simó, R.: Comparison of global climatological maps of sea surface dimethyl sulfide, Global Biogeochem. Cy., 18, GB3013, doi:10.1029/2003GB002193, 2004a.

Belviso, S., Moulin, C., Bopp, L., and Stefels, J.: Assessment of a global climatology of oceanic dimethylsulfide (DMS) concentrations based on SeaWiFS imagery (1998-2001), Can. J. Fish. Aquat. Sci., 61, 804-816, 2004b.

Bopp, L., Boucher, O., Aumont, O., Belviso, S., Dufresne, J. L., Pham, M., and Monfray, P.: Will marine dimethylsulfide emissions amplify or alleviate global warming? A model study, Cana. J. Fish. Aquat. Sci., 61, 826-835, 2004.

Boucher, O., Moulin, C., Belviso, S., Aumont, O., Bopp, L., Cosme, E., von Kuhlmann, R., Lawrence, M. G., Pham, M., Reddy, M. 
S., Sciare, J., and Venkataraman, C.: DMS atmospheric concentrations and sulphate aerosol indirect radiative forcing: a sensitivity study to the DMS source representation and oxidation, Atmos. Chem. Phys., 3, 49-65, doi:10.5194/acp-3-49-2003, 2003.

Carslaw, K. S., Boucher, O., Spracklen, D. V., Mann, G. W., Rae, J. G. L., Woodward, S., and Kulmala, M.: A review of natural aerosol interactions and feedbacks within the Earth system, Atmos. Chem. Phys., 10, 1701-1737, doi:10.5194/acp-10-17012010, 2010.

Charlson, R. J., Lovelock, J. E., Andreae, M. O., and Warren, S. G.: Oceanic phytoplankton, atmospheric sulfur, cloud albedo and climate, Nature, 326, 655-661, 1987.

Chin, M., Rood, R. B., Allen, D. J., Andreae, M. O., Thompson, A. M., Lin, S. J., Atlas, R. M., and Ardizzone, J. V.: Processes controlling dimethylsulfide over the ocean: Case studies using a 3-D model driven by assimilated meteorological fields, J. Geophys. Res.-Atmos., 103, 8341-8353, 1998.

Chin, M. A. and Jacob, D. J.: Anthropogenic and natural contributions to tropospheric sulfate: A global model analysis, J. Geophys. Res.-Atmos., 101, 18691-18699, 1996.

Chin, M. A., Jacob, D. J., Gardner, G. M., ForemanFowler, M. S., Spiro, P. A., and Savoie, D. L.: A global three-dimensional model of tropospheric sulfate, J. Geophys. Res.-Atmos., 101, 18667-18690, 1996.

Chipperfield, M. P.: New version of the TOMCAT/SLIMCAT offline chemical transport model: Intercomparison of stratospheric tracer experiments, Q. J. Roy. Meteor. Soc., 132, 1179-1203, 2006.

Chu, S. P., Elliott, S., and Maltrud, M. E.: Global eddy permitting simulations of surface ocean nitrogen, iron, sulfur cycling, Chemosphere, 50, 223-235, 2003.

Dentener, F., Kinne, S., Bond, T., Boucher, O., Cofala, J., Generoso, S., Ginoux, P., Gong, S., Hoelzemann, J. J., Ito, A., Marelli, L., Penner, J. E., Putaud, J.-P., Textor, C., Schulz, M., van der Werf, G. R., and Wilson, J.: Emissions of primary aerosol and precursor gases in the years 2000 and 1750 prescribed data-sets for AeroCom, Atmos. Chem. Phys., 6, 4321-4344, doi:10.5194/acp6-4321-2006, 2006.

Erickson, D. J.: A Stability Dependent Theory For Air-Sea GasExchange, J. Geophys. Res.-Oceans, 98, 8471-8488, 1993.

Friedlingstein, P., Bopp, L., Ciais, P., Dufresne, J. L., Fairhead, L., Le Treut, H., Monfray, P., and Orr, J.: Positive feedback between future climate change and the carbon cycle, Geophys. Res. Lett., 28, 1543-1546, 2001.

Gondwe, M., Krol, M., Gieskes, W., Klaassen, W., and de Baar, H.: The contribution of ocean-leaving DMS to the global atmospheric burdens of DMS, MSA, SO2, and NSS SO4, Global Biogeochem. Cy., 17, 1056, doi:10.1029/2002GB001937, 2003.

Gong, S. L.: A parameterization of sea-salt aerosol source function for sub- and super-micron particles, Global Biogeochem. Cy., 17, 1097, doi:10.1029/2003GB002079, 2003.

Halloran, P., Bell, T. G., and Totterdell, I. J.: Can we trust empirical marine DMS parameterisations within projections of future climate?, Biogeosciences, 7, 1645-1656, doi:10.5194/bg-7-16452010, 2010.

Jourdain, B. and Legrand, M.: Seasonal variations of atmospheric dimethylsulfide, dimethylsulfoxide, sulfur dioxide, methanesulfonate, and non-sea-salt sulfate aerosols at Dumont d'Urville (coastal Antarctica) (December 1998 to July 1999), J. Geophys.
Res.-Atmos., 106, 14391-14408, 2001.

Kettle, A. J. and Andreae, M. O.: Flux of dimethylsulfide from the oceans: A comparison of updated data seas and flux models, J. Geophys. Res.-Atmos., 105, 26793-26808, 2000.

Kettle, A. J., Andreae, M. O., Amouroux, D., Andreae, T. W., Bates, T. S., Berresheim, H., Bingemer, H., Boniforti, R., Curran, M. A. J., DiTullio, G. R., Helas, G., Jones, G. B., Keller, M. D., Kiene, R. P., Leck, C., Levasseur, M., Malin, G., Maspero, M., Matrai, P., McTaggart, A. R., Mihalopoulos, N., Nguyen, B. C., Novo, A., Putaud, J. P., Rapsomanikis, S., Roberts, G., Schebeske, G., Sharma, S., Simó, R., Staubes, R., Turner, S., and Uher, G.: A global database of sea surface dimethylsulfide (DMS) measurements and a procedure to predict sea surface DMS as a function of latitude, longitude, and month, Global Biogeochem. Cy., 13, 399-444, 1999.

Kistler, R., Kalnay, E., Collins, W., Saha, S., White, G., Woollen, J., Chelliah, M., Ebisuzaki, W., Kanamitsu, M., Kousky, V., van den Dool, H., Jenne, R., and Fiorino, M.: The NCEP-NCAR 50year reanalysis: Monthly means CD-ROM and documentation, B. Am. Meteorol. Soc., 82, 247-267, 2001.

Kloster, S., Feichter, J., Maier-Reimer, E., Six, K. D., Stier, P., and Wetzel, P.: DMS cycle in the marine ocean-atmosphere system a global model study, Biogeosciences, 3, 29-51, doi:10.5194/bg3-29-2006, 2006.

Kloster, S., Six, K. D., Feichter, J., Maier-Reimer, E., Roeckner, E., Wetzel, P., Stier, P., and Esch, M.: Response of dimethylsulfide (DMS) in the ocean and atmosphere to global warming, J. Geophys. Res.-Biogeo., 112, G03005, doi:10.1029/2006JG000224, 2007.

Korhonen, H., Carslaw, K. S., Spracklen, D. V., Mann, G. W., and Woodhouse, M. T.: Influence of oceanic dimethyl sulfide emissions on cloud condensation nuclei concentrations and seasonality over the remote Southern Hemisphere oceans: A global model study, J. Geophys. Res.-Atmos., 113, D15204, doi:10.1029/2007JD009718, 2008.

Korhonen, H., Carslaw, K. S., Forster, P. M, Mikkonen, S., Gordon, N. D., and Kokkola, H.: Aerosol climate feedback due to decadal increases in southern hemisphere wind speeds, Geophys. Res. Lett., 37, L02805, doi:10.1029/2009GL041320, 2010.

Kulmala, M., Laaksonen, A., and Pirjola, L.: Parameterizations for sulfuric acid/water nucleation rates, J. Geophys. Res.-Atmos., 103, 8301-8307, 1998.

Langner, J. and Rodhe, H.: A Global 3-Dimensional Model Of The Tropospheric Sulfur Cycle, J. Atmos. Chem., 13, 225-263, 1991.

Le Quéré, C. L., Harrison, S. P., Prentice, I. C., Buitenhuis, E. T., Aumont, O., Bopp, L., Claustre, H., Da Cunha, L. C., Geider, R., Giraud, X., Klaas, C., Kohfeld, K. E., Legendre, L., Manizza, M., Platt, T., Rivkin, R. B., Sathyendranath, S., Uitz, J., Watson, A. J., and Wolf-Gladrow, D.: Ecosystem dynamics based on plankton functional types for global ocean biogeochemistry models, Glob. Change Biol., 11, 2016-2040, 2005.

Liss, P. S. and Merlivat, L.: The Role of Air-Sea Gas Exchange in Geochemical Cycling, chap. Air-sea gas exchange rates: Introduction and synthesis, D. Reidel, Norwell, Mass., USA, 113127, 1986.

Liss, P. S., Malin, G., Turner, S. M., and Holligan, P. M.: Dimethyl Sulfide And Phaeocystis - A Review, J. Marine Syst., 5, 41-53, 1994.

Liss, P. S., Hatton, A. D., Malin, G., Nightingale, P. D., and Turner, 
S. M.: Marine sulphur emissions, Philos. T. Roy. Soc. B, 352, 159-168, 1997.

Longhurst, A., Sathyendranath, S., Platt, T., and Caverhill, C.: An Estimate Of Global Primary Production In The Ocean From Satellite Radiometer Data, J. Plankton Res., 17, 1245-1271, 1995.

Manktelow, P. T., Carslaw, K. S., Mann, G. W., and Spracklen, D. V.: The impact of dust on sulfate aerosol, $\mathrm{CN}$ and $\mathrm{CCN}$ during an East Asian dust storm, Atmos. Chem. Phys., 10, 365-382, doi:10.5194/acp-10-365-2010, 2010.

Manktelow, P. T.: Understanding the Complex Behaviour of Tropospheric Sulfate in a Global Aerosol Microphysics Model, Ph.D. thesis, School of Earth and Environment, University of Leeds, 2008.

Manktelow, P. T., Mann, G. W., Carslaw, K. S., Spracklen, D. V., and Chipperfield, M. P.: Regional and global trends in sulfate aerosol since the 1980s, Geophys. Res. Lett., 34, L14803, doi:10.1029/2006GL028668, 2007.

Mann, G. W., Carslaw, K. S., Spracklen, D. V., Ridley, D. A., Manktelow, P. T., Chipperfield, M. P., Pickering, S. J., and Johnson, C. E.: Description and evaluation of GLOMAP-mode: a modal global aerosol microphysics model for the UKCA composition-climate model, Geosci. Model Dev. Discuss., 3, 651-734, doi:10.5194/gmdd-3-651-2010, 2010.

Mårtensson, E. M., Nilsson, E. D., de Leeuw, G., Cohen, L. H., and Hansson, H. C.: Laboratory simulations and parameterization of the primary marine aerosol production, J. Geophys. Res.-Atmos., 108, 4297, doi:10.1029/2002JD002263, 2003.

Merikanto, J., Spracklen, D. V., Mann, G. W., Pickering, S. J., and Carslaw, K. S.: Impact of nucleation on global CCN, Atmos. Chem. Phys., 9, 8601-8616, doi:10.5194/acp-9-8601-2009, 2009

Nguyen, B. C., Mihalopoulos, N., Putaud, J. P., Gaudry, A., Gallet, L., Keene, W. C., and Galloway, J. N.: Covariations In Oceanic Dimethyl Sulfide, Its Oxidation-Products And Rain Acidity At Amsterdam Island In The Southern Indian-Ocean, J. Atmos. Chem., 15, 39-53, 1992.

Nightingale, P. D., Malin, G., Law, C. S., Watson, A. J., Liss, P. S., Liddicoat, M. I., Boutin, J., and Upstill-Goddard, R. C.: In situ evaluation of air-sea gas exchange parameterizations using novel conservative and volatile tracers, Global Biogeochem. Сy., 14, 373-387, 2000

Palmer, J. R. and Totterdell, I. J.: Production and export in a global ocean ecosystem model year, Deep-Sea Res. Pt. I, 48(5), 11691198, 2001,

Pham, M., Muller, J. F., Brasseur, G. P., Granier, C., and Megie, G.: A three-dimensional study of the tropospheric sulfur cycle, J. Geophys. Res.-Atmos., 100, 26061-26092, 1995.

Simó, R. and Dachs, J.: Global ocean emission of dimethylsulfide predicted from biogeophysical data, Global Biogeochem. Cy., 16, 1078, doi:10.1029/2001GB001829, 2002.

Spracklen, D. V., Pringle, K. J., Carslaw, K. S., Chipperfield, M. P., and Mann, G. W.: A global off-line model of sizeresolved aerosol microphysics: I. Model development and prediction of aerosol properties, Atmos. Chem. Phys., 5, 22272252, doi:10.5194/acp-5-2227-2005, 2005
Stefels, J., Steinke, M., Turner, S., Malin, G., and Belviso, S.: Environmental constraints on the production and removal of the climatically active gas dimethylsulphide (DMS) and implications for ecosystem modelling, Biogeochemistry, 83, 245-275, doi:10.5194/acp-83-245-2007, 2007.

Stier, P., Feichter, J., Kinne, S., Kloster, S., Vignati, E., Wilson, J., Ganzeveld, L., Tegen, I., Werner, M., Balkanski, Y., Schulz, M., Boucher, O., Minikin, A., and Petzold, A.: The aerosolclimate model ECHAM5-HAM, Atmos. Chem. Phys., 5, 11251156, doi:10.5194/acp-5-1125-2005, 2005.

Timmermann, R., Goosse, H., Madec, G., Fichefet, T., Ethe, C., and Duliere, V.: On the representation of high latitude processes in the ORCA-LIM global coupled sea ice-ocean model, Ocean Model., 8, 175-201, 2005.

Trenberth, K. E., Jones, P. D., Ambenje, P., Bojariu, R., Easterling, D., Klein Tank, A., Parker, D., Rahimzadeh, F., Renwick, J. A., Rusticucci, M., Soden, B., and Zhai, P.: Observations: Surface and Atmospheric Climate Change. In: Climate Change 2007: The Physical Science Basis. Contribution of Working Group I to the Fourth Assessment Report of the Intergovernmental Panel on Climate Change, Cambridge University Press, Cambridge, UK and New York, NY, USA, 2007.

Uppala, S. M., Kallberg, P. W., Simmons, A. J., Andrae, U., Bechtold, V. D., Fiorino, M., Gibson, J. K., Haseler, J., Hernandez, A., Kelly, G. A., Li, X., Onogi, K., Saarinen, S., Sokka, N., Allan, R. P., Andersson, E., Arpe, K., Balmaseda, M. A., Beljaars, A. C. M., Van De Berg, L., Bidlot, J., Bormann, N., Caires, S., Chevallier, F., Dethof, A., Dragosavac, M., Fisher, M., Fuentes, M., Hagemann, S., Holm, E., Hoskins, B. J., Isaksen, L., Janssen, P. A. E. M., Jenne, R., McNally, A. P., Mahfouf, J. F., Morcrette, J. J., Rayner, N. A., Saunders, R. W., Simon, P., Sterl, A., Trenberth, K. E., Untch, A., Vasiljevic, D., Viterbo, P., and Woollen, J.: The ERA-40 re-analysis, Q. J. Roy. Meteor. Soc., 131, 29613012, 2005.

Vallina, S. M. and Simó, R.: Strong relationship between DMS and the solar radiation dose over the global surface ocean, Science, 315, 506-508, 2007.

Vallina, S. M., Simó, R., and Manizza, M.: Weak response of oceanic dimethylsulfide to upper mixing shoaling induced by global warming, Proceedings Of The National Academy Of Sciences Of The United States Of America, 104, 16004-16009, 2007.

Vogt, M., Vallina, S., Buitenhuis, E., Bopp, L., and Le Quéré, C.: Simulating Dimethylsulphide Seasonality with the Dynamic Green Ocean Model PlankTOM5, J. Geophys. Res.-Ocean, 115, C06021, doi:10.1029/2009JC005529, 2010.

Wanninkhof, R.: Relationship Between Wind-speed and Gasexchange Over the Ocean, J. Geophys. Res.-oceans, 97, 73737382, 1992.

Woodhouse, M. T., Mann, G. W., Carslaw, K. S., and Boucher, O.: New Directions: The impact of oceanic iron fertilisation on cloud condensation nuclei, Atmos. Environ., 42, 5728-5730, 2008. 